\title{
Features of additive technologies implementation in aerospace equipment production
}

\author{
Yuri Morgunov ${ }^{1, *}$, Boris Saushkin ${ }^{1}$ \\ ${ }^{1}$ Moscow Polytechnic University, Moscow 107023, Russia
}

\begin{abstract}
Additive technologies (AT) are effective when processing relatively small batches of products, when high costs of materials is compensated by lowering fixed costs which are related to the use of traditional technologies. Aerospace equipment production is characterized, as a rule, within single and serial (small and medium series) types of production, which is why additive technologies will be in high demand in this field of engineering production. There is a necessary condition, regarding the widespread implementation and spreading of new technologies. It is its technical and economic efficiency. This article provides specific information on the comparative characteristics of classic and additive technologies of the common purpose and some pros and cons of these technologies. The main disadvantage of layer-by-layer synthesis of complexly shaped products is a relatively long duration of machine processing, resulting in high production costs, depreciation of equipment, and calculation of net costs. It is also noted that the feasibility study of AT use leads to reducing the number of workers and costs for maintaining on-site life safety. Also the usage of AT will lead to the reduction of shop and factory overhead costs due to cheaper logistics. In the field of aerospace engineering the major and promising direction of work in the field of additive manufacturing is to improve the technologies and equipment for the synthesis of products of ceramic and composite materials.
\end{abstract}

\section{Introduction}

Adoption of additive technologies and additive manufacturing at mechanical engineering enterprises is a widely discussed subject of scientific and engineering literature [1-5]. There is a notable demand for such technology in the military-industrial complex [6], particularly in aerospace engineering [7-12].

When making an aircraft, the following advantages of additive technology are of particular importance:

1. Structural complexity of a product can reduce its mass. Truly, it costs 12 to 25 thousand dollars to deliver one kilogram of mass to the Earth's orbit; reducing the mass of a long-haul aircraft by $100 \mathrm{~kg}$ saves $\$ 2.5$ million and reduced $\mathrm{CO} 2$ emissions by 1.3 million tons over its entire lifetime.

2.A significant increase in the materials utilization factor (MUF). In conventional manufacturing of the essential aerospace engineering parts, the MUF is 0.05 to 0.2 . Use of AT increases that factor to $0.7-0.9$, leading to a significant reduction in the cost of expensive materials.

3. Reducing cycle time and the pre-production costs of new products are of utmost importance, especially in pilot manufacturing. AT developments enable pilot-plan organizations not only to carry out rapid full-scale modeling of the composite parts of a pilot product, but also to speed up both the manufacturing of complex parts and adjustments in their design in the process of fine-tuning and testing. Reportedly, use of AT in manufacturing the five essential parts of a liquid-jet engine makes the manufacturing cycle five times shorter on average.

4. Replacing an assembly unit with a single part item makes the composite parts of a product more reliable while also shortening their manufacturing cycle. For instance, there is only one to three part items in the additive manufacturing of an injector, cf. 138 items in conventional manufacturing.

5.The critical parts of engine hot sections made of materials of low cutting machinability become less labor-intensive and costly to manufacture.

6. Additive shaping technologies are more flexible than any conventional technology because a changeover to another part does not require new workpieces and tooling. That is why AT are efficient for machining relatively small batches, where the high material costs are offset by cutting the fixed costs associated with conventional technology. Aerospace engineering is generally about single, small-batch and medium-batch manufacturing, which is why additive technologies will enjoy particular demand in this industry.

Calculations performed by one of the leading enterprises in the industry show that additive manufacturing of a number of products, on average, increase the MUF to $0.7-0.9$, make the manufacturing

\footnotetext{
Corresponding author: morgunov56@mail.ru
} 
cycle for five products five times shorter, whereas such manufacturing requires several times less pre-production time and becomes 5-6 times less costly. Table 1 presents specific calculation results for one such product.

Note that as of 2013, the share of aerospace industry in the world additive technology market is about $12 \%$ (2013) and tends to increase. Some technologies that are widely used and are sometimes critical in this industry are essentially additive technologies; however, they are barely discussed in additive technology papers due to their specific nature.

Table 1. Comparison of injector manufacturing technologies.

\begin{tabular}{lcccc}
\hline \multicolumn{1}{c}{ Options compared } & $\begin{array}{c}\text { Number } \\
\text { of parts }\end{array}$ & $\begin{array}{c}\text { Number of } \\
\text { operations } \\
\text { per } \\
\text { technology }\end{array}$ & $\begin{array}{c}\text { Labor } \\
\text { intensity, } \\
\mathbf{n} / \mathbf{h}\end{array}$ & $\begin{array}{c}\text { Manufacturing } \\
\text { cycle, days }\end{array}$ \\
\hline $\begin{array}{l}\text { Subtractive } \\
\text { technology+Assembly }\end{array}$ & 138 & 12 & 1025 & 56 \\
\hline $\begin{array}{l}\text { Additive } \\
\text { technology+Assembly }\end{array}$ & $3(1)$ & 2 & 77 & 7 \\
\hline
\end{tabular}

This applies to technology related to the winding of carbon, glass, or polymer fiber products on the winding machines where such products are binder-impregnated and then cured [13].

\section{Organizational and economic issues; discussion thereof}

Techno-economic efficiency of a new technology is a pre-requisite for its wide adoption and spread. The papers on AM economics are not numerous [14, 15], which causes certain difficulties for professionals involved in the implementation and adoption of such technology. From the formal-technological standpoint, adopting an additive technology makes sense for a particular enterprise only if it cuts the per-unit manufacturing costs (the total specific resource costs) ceteris paribus. Therefore, to study the techno-economic feasibility of adopting an additive technology at an enterprise, one first has to calculate the shop costs of making a part or an assembly unit, and the difference in such costs for two technological options:

- the existing manufacturing technology using the mastered methods of workpiece making, machining, and assembly (MT1);

- a manufacturing technology based on additive shaping operations (MT2).

Given the above, the structure of manufacturing and assembly costs for the first option can be written as follows

$$
C_{1}=\sum_{i=1}^{m}\left(C_{13 i}+C_{1 M i}\right)+C_{c 6}
$$

for the second option, as follows:

$$
C_{2}=C_{p r}+C_{a d}+C_{p s}
$$

where $C_{1}, C_{2}$ are the total final product manufacturing costs for the manufacturing options under comparison, $\mathrm{C}_{13 i}$ is the cost of making a workpiece for the $i$ th part of an assembly unit, $\mathrm{C}_{1 \mathrm{м} i}$ the cost of machining the $i$ th part, $m$ is the number of assembly unit parts manufactured, $C_{\text {cб }}$ is the cost of assembling a composite part with due account of the costs of other components per the assembly unit specifications, $C_{\text {пр }}$ is the cost of preliminary operations, $C_{\text {ад }}$ is the cost of additive shaping operations, $C_{\text {пс }}$ is the cost of subsequent finishing operations.

Note that additive technologies of layer-by-layer powder-based manufacturing do not eliminate residual porosity, which in some cases necessitates further steps like hot isostatic pressing, infiltration, and heat treatment. Reportedly, only $19 \%$ of all additive manufacturing products are used as final products.

The general approach to solving this problem is presented in [15]. Let us discuss the effect of this technological option on the most important costs that it would change.

The difference in the costs of materials $\Delta C_{\mathrm{M}}$ for the options under comparison is calculated based on the wholesale prices per unit mass of materials and waste, on the material utilization rate, and the mass of waste per product unit [16]. Table 2 presents data on the prices of some powdered materials in the non-Russian market as well as based on commercial offers of some companies in the Russian market [1]. The bottom row contains the weighted average prices of rolled materials (30 to $100 \mathrm{~mm}$ in diameter); the prices were obtained by analyzing commercial offers found on the Internet. The data presented show that the price of powder for SLM is an order of magnitude higher than the prices of rolled materials used for workpiece manufacturing.

Table 2. Prices of some powdered materials and corresponding

\begin{tabular}{|c|c|c|c|c|c|}
\hline \multirow{2}{*}{$\begin{array}{l}\text { Origins of } \\
\text { the price }\end{array}$} & \multicolumn{5}{|c|}{ Material } \\
\hline & $T i-6 A L-4 V$ & $\mathrm{Co}-\mathrm{Cr}$ & AlSi12 & $\begin{array}{c}\text { Spesial } \\
\text { steel }\end{array}$ & $\begin{array}{c}\text { Inconel } \\
625\end{array}$ \\
\hline $\begin{array}{l}\text { Wholesale } \\
\text { price in non- } \\
\text { Russian } \\
\text { markets }\end{array}$ & $200-300$ & 150 & $70-90$ & $70-80$ & 75 \\
\hline $\begin{array}{l}\text { SLM } \\
\text { Solutions }\end{array}$ & 520 & 210 & 60 & 130 & 160 \\
\hline EOS & 485 & 320 & 122 & 235 & - \\
\hline $\begin{array}{l}\text { Rolled rods in } \\
\text { Russia (RUB) }\end{array}$ & $\begin{array}{c}17-25 \\
(1300-1900)\end{array}$ & - & $\begin{array}{c}3-5 \\
(230-350)\end{array}$ & $\begin{array}{c}3-4 \\
(200-270)\end{array}$ & - \\
\hline
\end{tabular}
rolled materials $(\mathrm{Eu} / \mathrm{kg})$.

In case of layer-by-layer sintering (melting) with a laser beam or an electron beam, some portion of the powder in contact with the contour of the solid being formed will be partially sintered or melted and removed in subsequent screening. Supports are used for relatively bulky and complexly shaped parts. This results in waste and the materials utilization factor amounting to $0.7-0.9$. For the critical complexly shaped aerospace equipment parts manufactured per $\mathrm{MT}_{1}$, this factor equals 0.05 to 0.2 .

These data allow estimating the ratio of material costs of additive shaping $\left(C_{\mathrm{M} 2}\right)$ to the ratio of material 
costs in machining $\left(C_{\mathrm{M} 1}\right)$; it equals 0.5 to 5 . So it is seen that despite the high price of powdered materials, the difference $\Delta C_{\mathrm{M}}$ can be positive or negative. Note that powders tend to become cheaper, with forecasts being made their prices will decline by $75 \%$.

Direct worker wages for each manufacturing option are calculated by summing per the number of operations in either MT [16]. The comparative calculations in this case are peculiar because of the following.

First, additive shaping requires considerably less operations to manufacture a part. Second, the per-unit time spent on additive shaping operations usually amounts to dozes of hours. As modern equipment can operate automatically for long periods of time, it makes sense to apply multiple-machine servicing and multitasking to operate it. As a result, the machine and labor intensity of the operation differ significantly.

Analysis reveals that the labor intensity of additive shaping operations is relatively low. According to ZAO Globatek CG, only an hour of direct labor is required to manufacture a single part type bush, whereas the machine time amounts to $20-40$ hours. As there are no direct labor standards, wages for direct workers involved in additive shaping operations shall be determined experimentally when adopting and mastering new equipment.

When making calculations, one needs to estimate the per-unit time spent on additive shaping operations. Using the classical standard time structure is difficult in this case due to the lack of standards that would help determine its components. At a factory, one has to use statistical methods to determine those components by means of timekeeping and working day photographs. Calculating the machine time is difficult due to the lack of reference formulas and the way these formulas depend on the method of additive shaping. That is why an expression for calculating the machine or operating time is obtained for each additive shaping method based on the existing methodology of valuating the operations with due account of the specifics of the physicochemical processes occurring in producing bulk solid forms in each case. For example, the following expression it recommended for calculating the product buildup time $t_{\mathrm{o}}$ when layering a 3D form, for instance by selective laser sintering.

$$
t_{0}=t_{M}+t_{V 1}+t_{V 2}=\sum_{i=1}^{m}\left(\frac{F_{i}}{k_{\mathrm{p}} d_{p}^{2} \phi_{V l}}+t_{i}^{P S}\right)+t_{V 2}
$$

where $t_{\mathrm{M}}$ is the machine time determined by moving the light contact spot on the layer contour, $t_{\mathrm{B} 1}$ is a portion of additional time needed to prepare the shaping of selected layers, $t_{\mathrm{B} 2}$ are the remaining portions of additional time (unloading, possible technological delays, cycle initiation), $m$ is the number of selected layers, $d_{\Pi}{ }^{{ }^{\dagger}}$ is the effective diameter of the laser-powder contact spot, $k_{\mathrm{\Pi}}$ is the overlapping coefficient, $F_{i}$ is the area of the $i$ th layer, $\delta_{i}$ is the distance of the route the contact spot center point has to travel to trace that area, $v_{л}$ is the mean contact spot speed when moving along this route, $t_{\mathrm{i}}{ }^{\text {пc }}$ is the time to prepare to walk around the $j$ th layer.
For a more accurate calculation of the machine time, one has to take into account the light spot tracing strategy for the contour of area $F_{i}$ and to calculate the distance of the route for $\delta_{i}$ each layer. This case

$$
t_{m}=\sum_{i=1}^{m} \frac{\delta_{i}}{v_{L}}
$$

From the equations above, we conclude the operating time depends on the number of layers, the method of division into layers, the chosen tracing strategy, and the mean contact spot movement speed. As one can see, a significant portion of operating time is spent to prepare the layer for sintering $\left(t_{\mathrm{B} 1}\right)$. SLM Solutions discarded the conventional way to form the powder layer by feeding the powder from below with a piston; instead, it has developed and patented a method of feeding the powder 'from above' which requires less strokes of the evener, reduces $t_{\mathrm{B} 1}$ and improves performance.

The effect of these factors results in a significant different in buildup time for machines made by different companies. Machine time can be estimated less accurately where the $3 \mathrm{D}$ performance of the machine in specified modes $\left(\Pi_{v}\right)$ and the calculated volume $\left(V_{\mathrm{p}}\right)$ of the part are known; such estimation shall take into account possible additional builds.

The main drawback of layer-by-layer synthesis of spatio-complex products is that it requires relatively long machine time. This results in a greater proportion of $\mathrm{Ca}$ equipment depreciation costs in cost calculations. As such equipment is very expensive $(0.3 \ldots 1.5$ million Euro depending on the manufacturer, the standard size, the options, the delivery terms, etc.), this item of costs can sometimes be crucial. Reportedly, machine depreciation costs can amount in some cases to $70 \%$ of the cost of the product. To reduce the costs per this item, it is recommended to maximize operations and operate such equipment without downtime, preferably in two or three shifts. Due to such equipment quickly becoming obsolescent, the payback period shall not exceed five years.

An important advantage of the second manufacturing option is a sharp decrease in tool and tooling specific costs, as a rule $\Delta C_{\text {и }}>0$ and $\Delta C_{\text {пр }}>0$. It is not difficult to calculate the remaining components of costs.

To improve the economic indicators of additive technology adoption, it is recommended to equip the additive shaping shop section with multiple machines having various capacities, such as SLM 50 (100 Watts, $12 \mu \mathrm{m}$ spot $)+$ SLM $300(400 \mathrm{~W}, 50 \mu \mathrm{m})$ :

When using an additive technology, the enterprise needs less workers and spends less on safety measures; shot and factory overhead costs are reduced thanks to lower logistics costs. These advantages may also be taken into account when studying the techno-economic feasibility of such technologies.

\section{Conclusions}

Developing new methods different from layer-by-layer synthesis is an effective way to improve additive shaping performance. We would like to note the brand new 
additive shaping method based on $3 \mathrm{D}$ synthesis from a liquid interface. This method, referred to as continuous liquid interface production (CLIP), boasts significantly higher shaping rate that is 25 to 1000 times, and experts believe could be 1000 times greater than that of layerby-layer synthesis. It also features structure and property isotropy of manufactures objects, low surface roughness, and high printing resolution. It is expected to enable realtime manufacture of spatiocomplex objects with functional properties matching the finished product specifications.

We would like to stress the trend towards the development of combined technology and equipment, to emphasize how promising this area is for mechanical engineering. Such technologies will further reduce the manufacturing cycle and will feature the pros of both subtractive and additive methods. Solidica has developed Ultrasonic Additive Manufacturing (UAM) technology; Fabrisonic uses this technology in its hybrid SonicLayer R200 machines that are capable of additive-subtractive machining of products made of ductile metals and composite materials with a metal or a polymer matrix. Mitsubishi LUMEX has begun delivering its integrated Avance-25 Hermle complex that combined SLS and 5-axle milling. Hermle has announced it is going to start manufacturing is MPA-40 complex that combined 5-axle milling and 3D-gas-dynamic spraying. Use of such technologies and corresponding machine systems will also necessitate a techno-economic feasibility study with due account of the specifics above.

For aerospace engineering, it is important and promising to enhance the technology and equipment for the synthesis of products of ceramic and composite materials [18].

\section{References}

1. M.A. Zlenko, A.A. Popovich, I.M. Mutyilina, Additive technologies in mechanical engineering (Politechnical University, St. Petersburg, 2013)
2. I.V. Shishkovskiy, Fundamentals of high-resolution additive technologies (Piter, St. Petersburg, 2015)

3. Ya. Gibson, D. Rozen, B. Staker, Additive Production Technologies (Tehnosfera, Moscow, 2016)

4. Public analytical report on development of new production technologies. Skolkovo Institute of Science and Technology (2014)

5. W.E. Frazier, A Review, J. Mater, Metal Additive Manufacturing Eng. Performance, 23(6), 1917-1928 (2014)

6 Yu.M. Mihaylov, Prospects for the use of additive technologies in the DIC (Moscow, 2015)

7. O.S. Sirotkin, Aviation industry, 2, 22-25 (2015)

8. D. M. Chumakov, Works MAI, 78. http://www.mai.ru/science/trudy/

9. V.A. Isachenko, Yu.P. Astahov, B.P. Saushkin, Technology of mechanical engineering, 1, 10-14 (2016)

10. Yu.P. Astahov, S.A. Kochergin, Yu.A. Morgunov, B.P. Saushkin, Technology of mechanical engineering, 5, 14-18 (2013)

11. Yu.A. Morgunov, B.P. Saushkin, Additive technologies, 1, 30-38 (2016)

12. Yu.A. Morgunov, B.P. Saushkin, Rhythm of Mechanical Engineering, 9, 26-31 (2016)

13. D.V. Panov, B.P. Saushkin, A.N. Korotkov, Rhythm 7, 32-36 (2014)

14. E. Atzeni, A. Salmi, Int. J. Adv. Manuf. Tech., 62(9), 1147-1155 (2012)

15. Yu.A. Morgunov, B.P. Saushkin, High technology in engineering, 7, 28-35 (2016)

16. K. M. Velikanova, Calculations of economic efficiency of new technology (Mashinostroenie, Leningrad, 1990)

17. J.R. Tumbleston, Science, 347, 1349 (2015)

18. N. Travitzky, A. Bonet, B. Dermeik, Adv. Eng. Mater., 16(6), 729-753 (2014) 